\title{
Decisions of Accounting Standards and Discussions of Collective Choice under Visual Angle of Public Management
}

\author{
Wenmiao Zhang \\ Finance and Taxation College, Shandong University of Finance and Economics, Jinan, China \\ Email: 1509122636@qq.com \\ Received 6 October 2014; revised 5 November 2014; accepted 12 November 2014 \\ Copyright (C) 2014 by author and Scientific Research Publishing Inc. \\ This work is licensed under the Creative Commons Attribution International License (CC BY). \\ http://creativecommons.org/licenses/by/4.0/

(c) (i) Open Access

\begin{abstract}
Accounting standards are integral components of economic policies; objectives of accounting standards reflect objectives of economic policies. Obviously, accounting standards play an indispensable role in promoting the orderly and stable development of the economy. This article expounds the relationship between different accounting standards and economic policies; accounting standards attribute and influence factors in the setting process of Chinese accounting standards. Under visual angle of public management, this essay analyses every relevant stakeholder's influence degree and choice behavior in the setting process of accounting standards, especially the function and behavior of the government. The conclusion is that high-quality accounting standards can be formulated in the case of the government's leading and other relevant stakeholder's common participation. Only in this way can we work out the optimal accounting standards for Chinese situations.
\end{abstract}

\section{Keywords}

Public Management Theory, Accounting Standards, Stakeholders, The Government, Collective Choice, Public Choice Theory, Policy Analysis Theory

\section{Introduction}

\subsection{Accounting Standards Are Integral Components of Economic Policies}

Macroeconomic policies include macroscopic accounting policies (accounting standards); microeconomic policies consist of microcosmic accounting policies. Obviously, accounting standards are integral components of economic policies, which are interworking with economic policies to promote the orderly and stable develop- 
ment of the economy.

Objectives of accounting standards reflect objectives of economic policies. In the entire economic management, the accounting standards are under the general goal of economic policies and the sub goal of economic policies' overall goals. Western economists generally hold that the objective of macroeconomic policies is to maximize the social welfare function, which specifically includes: first, the high degree of full employment which generally refers to the unemployment rate of $3 \%$; second, the stable price level measured with the price index which indicates the annual average moderate inflation of $2 \%, 3 \%$ and not more than $4 \%$ having a positive effect on the economic growth; third, the persistent and steady economic growth which is measured by average growth rate of GDP; fourth, equilibrium of balance of payments which includes the stable exchange rate and balance between imports and exports (Gao, 1988). Compared with it, the objective of microeconomic policies is to maximize the enterprise value.

About the objective of accounting standards, in theory, it is to minimize transaction costs and maximize the enterprise value (Chen et al., 1999). According to probes by present scholars, one opinion holds that the objective of accounting standards is to keep it efficient, fair and stable (Lin et al., 1998). To be more specific, the Pareto Principle is generally used to measure the efficiency of accounting standards and check whether accounting information in accordance with accounting standards causes the allocation of resources to achieve Pareto optimality. When the Lorenz curve and the Gini index measure the fairness condition of income distribution, accounting information in accordance with accounting standards has profound economic significance and economic consequences which ask for a fair and reasonable decision of accounting standards. Besides, the objective of accounting standards requires that accounting information in accordance with accounting standards should be beneficial to contribute to the stable, coordinated and sustainable development of social economy. Another point of view states that the decision of Chinese accounting standards has two goals (also known as "Twin Target Theory", Xue et al., 1997): to accounting standards for state-owned enterprises, they should be focused on government interests and intensively embody the requirements on enterprises' financial information proposed by the government ; to accounting standards for company system enterprises, their focuses should be on public interests, intensively embody the requirements on market economy operating mechanisms and stress the trueness and fairness of the financial information's reveal.

\subsection{Tracking of High-Quality Accounting Standards}

American Generally Accepted Accounting Principles, once recognized as the most perfect, comprehensive and specific accounting standards in the whole world, are the model esteemed by other countries' decision institutes for accounting standards including the International Accounting Standards Board, which are referred directly or indirectly by other countries' accounting standards. However, a series of financial scandals in the United States with Enron in 2001 as the originator cause people to rethink of American accounting standards and trigger worldwide debate on setting accounting standards' directs. U.S. Congress issues "Sarbanes-Oxley Act" and calls for researches on principles and directs of the U.S. financial reporting system.

Clearly, the United States is seeking the criteria for a balance between rules and principles under a new economic environment, which is not only to guide the company's financial reports to meet deals' substances but also provide the maneuverability with guiding space for accounting's treatments and reporting. From principle directs to rules and back to the objective directs, American Generally Accepted Accounting Principles' aim is to set up high-quality accounting standards. What are so called high-quality accounting standards? Robert K. Herdman, SEC Chief Accountant, in 2003 points that an ideal accounting standard should be principle-based, which requires financial reports reflect economic substances of transactions rather than forms and be regarded as the standard and core of optimal criterion.

\section{Public Management and Decision for Chinese Accounting Standards}

It is known that the substance overweighs the form, that is to say, in addition that legal forms should be checked when dealing with transactions, and more attentions [1] should be paid to their economic substances. In other words, accounting treatments should be in accordance with economic substances rather than legal forms of. As an integral part of macroeconomic policy, accounting standards are endowed with theories and methods of the use of public management ideas and the analysis of public policies. Researches on accounting standards from the view of policies (accounting standards is also one of economic policies) provide a new way of thinking for 
deciding accounting standards. As it is noted above, the aim for making researches on deciding accounting standards is to develop high-quality accounting standards. From the perspective of the policy analysis, the use of the public choice theory in the fields of finding and defining the economic substance and the potential goal reflected by accounting standards, aims to working out the optimal accounting standards for Chinese situations 1.

One of targets for researches on the relationship between policy analysis and accounting standards is to provide deciders for Chinese accounting standards with a thinking approach which is beneficial to working out accounting standards according to Chinese features. There is no doubt that a great many differences exist between Chinese culture and American culture and they are always deep-rooted and difficult to eliminate in the long historical period. When it comes to the practice, accounting standards are the outcome produced by various factors of politics, economy, culture and law in a country. Furthermore, under present historical conditions China's political, economic and other factors frequently have more significant impacts on accounting standards than the cultural factor. Therefore, cultural interpretations of accounting standards do not necessarily represent feasible and inevitable choices. If we recognize that the cultural traditions would affect accountants' values and decisions of accounting standards, it is undeniable that differences exist between national accounting standards. In other words, Chinese accounting standards can be close to the international accounting practice and refer to international experiences, but they are not identical to any country's accounting standards or the international accounting standards, which means that Chinese accounting standards will retain some accounting concepts and treatments with Chinese characteristic decided by Chinese unique cultural traditions.

From the perspective of the public choice theory, accounting standards are public product. Having strong externalities, they are speculations for accounting behaviors to regulate the distribution of benefits among stakeholders and aim for pursuing the equality and efficiency of economic consequences taken by accounting standards. However, in the reality of limited rationality, economic consequences of accounting standards are not always fair, which means that some interest groups acquire benefits while some suffer. Therefore, improving the quality of accounting standards is the requirement of every stakeholder. The government is both the producer and user of public goods which should be more concerned about the distribution of benefits among various interest groups. Accounting standards are treated as a system and in China the government is the principal part for working out them. So in the process of working out accounting standards the government should both comply with requirements of the accounting field and also be consistent with the general rules of policies. It is not enough for high-quality accounting standards to rely on the fairness of setting and restrictions of laws alone. The introduction of the public management theory into the formulation of accounting standards will make accounting standards more scientific and democratic.

\section{Accounting Standards: The Collective Choice for Relevant Stakeholders under the Public Choice Theory}

As institutional arrangements for regulating enterprises are to carry on activities of accounting recognition, measurement, recording and reporting, Accounting standards are a group of public contracts made by social relevant interest groups to reach an agreement on accounting procedures and methods. Also they are a result of a "consensus" reached by all the participants after repeated dice games, which is a special kind of public goods (Liu, 1996) and a collective choice achieved by relevant stakeholders under the public choice theory.

Accounting standards are a process of seeking concerted actions in a group for a target or multiple ones [2]. Individual preferences and goals involved in setting accounting encounter inconsistencies, or individual information can not be fully expressed or transferred, which makes groups difficult to make use of structured programs to obtain comparative complete information when making decisions. In researches on the public decisionmaking scientization, difficulties in interpersonal interactions and situational definitions and diversities in cultural backgrounds and value choices, increased difficulties of preference integrations in the process of making public decisions mistakes that occur in current Chinese accounting standards setting are related to the point that preferences not well integrated. Therefore, the analysis of stakeholders' preferences in accounting standards' setting is quite meaningful to develop high-quality accounting standards 2 .

\subsection{Interpretations of the Collective Choice According to the Public Choice Theory and the Policy Analysis Theory}

The public choice theory suggests that resources are always scarce and it is inevitable to start interest conflicts 
and competitions for resources. The public choice is a process that each participant in economic activities follows a rule, negotiates with each other and determines a plan for collective actions. The interest groups' motivation and principle is based on the "economic man", that is to say, the pursuit of the self-interest maximization. But the making of public policies, in fact, is the adjustment and reallocation of social values and resources (interests). Policies are not directed against a person. Instead they are always to all members of the society, or to a class of people, a group of people (a social class, stratum, group, population, etc.). However, the consistent social values and interests do not exist exactly, while only group and individual values and interests exist.

The policy analysis theory proposes that conflicts between interest groups by making policies are common. Because resources which the nation and the government can mobilize are limited and can not meet the requirements of all interest groups. An increase in an interest will certainly cause another to reduce. In developing policies, countries will inevitably be involved in various interest groups' values and interests. The process of adjustments and reallocations often makes damages on the original interests' balance among interest groups, which gives rise to their interests' conflicts. When a policy benefits a particular group and may make no benefit to or even damage another group, different reflections will appear. Beneficiaries will take some actions to maintain and support advantageous policies while impaired ones would be opposite to or change disadvantageous policies in some way.

Any policy acceptable to most groups expresses a kind of equilibrium. At this time, the policy has become a product of coordination and compromise made by a majority of interest groups and also the one of competition and struggle. If group's influence changes, equilibrium will be broken and a new round of balance for competition and struggle will begin. As a result, from some point of view the public policy can be seen as a process of interaction struggle, compromise and contracting between interest groups.

Therefore, the formation of accounting standards can be considered as a transaction process of a special contract that more than two participant negotiate and determine according to some rule, a public choice process and a run-in process between public contracts and private contracts.

\subsection{Every Relevant Stakeholder's Collective Choice in the Setting Process of Accounting Standards}

Since the formation of accounting standards is a transaction process of collective choices and special contracts, accounting standards obtain the high political nature (Table 1). When the introduction of an accounting standard is beneficial to interests of the group, through political spokesmen they will strongly instigate the introduction of accounting standards to be issued as soon as possible. When an accounting standard affects vital interests of a group, they will also make pressures on the government and try to block its introduction through some political means.

The setting process of American stock option accounting standards is a very obvious example. When FASB is ready to require a statement that the stock options would appear as an expense in the company's income sheet, it immediately meets oppositions from those large high-tech companies' directors and presidents, who ask the Securities and Exchange Commission "not to require the company to report compensation costs of stock option plans in the income statement". Even the U.S. president intervenes the matter. Finally, in the end of 1994 FASB has to compromise to encourage companies to use the fair value for confirming compensation costs of stock options rather than consider them as a mandatory requirement. Obviously, treating the accounting standards' setting as a pure process of developing technical specifications is biased.

\subsection{Behavior Analysis of the Government in Setting Accounting Standards}

From the point of the public management, the government is always in the leading position of administrative management actions. From the view of the public choice theory, the function of the government is to provide the community with the product which can not be obtained on their own and accounting standards are public goods whose formulation the government accounting standards should play a leading role in. Therefore, during many relevant stakeholders who set accounting standards, this article will be mainly focused on analyzing the government's actions in setting accounting standards. The results of historical researches on accounting standards show whoever has the right to setting accounting standards has the power of the resource's reallocation in fact (Liu, 1996). Viewed from arrangements of every country's right to setting accounting standards all over the world, accounting principles generally accepted in most countries are essentially set by the government. One 
Table 1. Every relevant stakeholder's influences on setting accounting standards.

\begin{tabular}{|c|c|c|c|}
\hline $\begin{array}{c}\text { Relevant } \\
\text { stakeholder }\end{array}$ & Motivation & Way & Importance \\
\hline Government & $\begin{array}{l}\text { Mostly focused on government's interests } \\
\text { and meanwhile inclined to the relevant } \\
\text { interest groups }\end{array}$ & $\begin{array}{l}\text { Setting “Active Rent Creation” and “Passive Rent } \\
\text { Creation” of the Generally Accepted Accounting Standards }\end{array}$ & Strong \\
\hline Shareholder & $\begin{array}{l}\text { Obtaining other companies' operating } \\
\text { information and pursuing profits }\end{array}$ & $\begin{array}{c}\text { Active participation and requirements for prior protection of } \\
\text { shareholders' interests }\end{array}$ & $\begin{array}{l}\text { Fairly } \\
\text { strong }\end{array}$ \\
\hline Operator & $\begin{array}{l}\text { Obtaining better operating performances } \\
\text { and compensations, earnings managements }\end{array}$ & $\begin{array}{l}\text { Convincing other relevant stakeholders to agree with } \\
\text { s accounting standards in their favors and not to participate in } \\
\text { the formulation of accounting standards }\end{array}$ & General \\
\hline Creditor & $\begin{array}{c}\text { Recovery of devoted principals and } \\
\text { interests }\end{array}$ & $\begin{array}{c}\text { Participating in the corporation's governance and } \\
\text { supervision but few opportunities to develop accounting } \\
\text { standards }\end{array}$ & General \\
\hline Staff & Wages and various benefits & $\begin{array}{c}\text { Concerned about the changes in accounting policies and } \\
\text { giving advice }\end{array}$ & General \\
\hline Public & Maximizing the egoism & Affecting the implementation of accounting standards & General \\
\hline
\end{tabular}

reason is that the accounting standard itself is an integral part of national economic policies and makes the government as an administrative institution for the implementation of macroeconomic policies that has the exclusive power resource of administrative law enforcement, which is conducive to the accounting order's formation of and stability and also avoids controversies of partial accounting treatments. One more reason is that based on the analysis of the public goods derived from the public choice theory, accounting standards is typical public goods, which is a result of the collective choice. The "Hobbes Standard Theorem" called by economists of modern property rights states that through establishing common accounting standards' structure the government makes it difficult for private agreements to reach minimal loss.

From accounting standards' history and developing trend, the government is always directly or indirectly controlling and mastering the administration authority of accounting information that is a kind of public goods, while accounting standards are a norm or an extension of the accounting information and naturally in control of the government. In other words, according to the principle of Pareto optimality, the government should have the formulation right of generally accepted accounting principles and the management authority should enjoy the formulation right of remaining accounting rules. Meanwhile, certified public accountants have functions to supervising whether the management authority follows common accounting standards and whether it exercises properly the formulation right of remaining accounting rules.

The government' role is to be further analyzed according to the enterprise information disclosure on cost effectiveness relationship. Accounting standards aim to provide better guiding principles for both sides' information exchanging, but the characteristics of accounting standards and the flexibility of accounting information disclosure allows companies possible to take means to evading accounting standards for promoting transfers of accounting information in capital markets to meet more with their own needs. Investors need reliable accounting information to help estimate expected values and investment risks. However, companies are not very likely to disclose all the information that investors want to know, which evolves both sides' economic dice games in the capital market into a dynamic dice game of the incomplete information (see Figure 1).

From the figure we can see that before developing accounting standards, the quantity and quality of the enterprise information disclosure is less than optimal. By comparisons, after accounting standards are developed, the government makes more strict requirements on the quantity and quality of the enterprise information disclosure in order to protect investors. Though the quantity and quality of the enterprise information disclosure are more than the optimum number, the cost is rather high and even much higher than what they are willing to pay before. In the meantime, the enterprise's effectiveness is insufficient and less than the optimal effectiveness combination. The kind of flexibility for implementing specific accounting standards and accounting policies allows the enterprise for the tendency to decrease the quantity and quality of the accounting information when it is disclosed 3. It can be seen that the government is very crucial in maintaining social economies' stability and orderly development [3].

In the book of “Accounting Standard Research”, Lin Zhonggao borrows three formulas of the theory of utility function and analyzes the questi [4] on of the behavior efficiency for the government in formulation of account- 


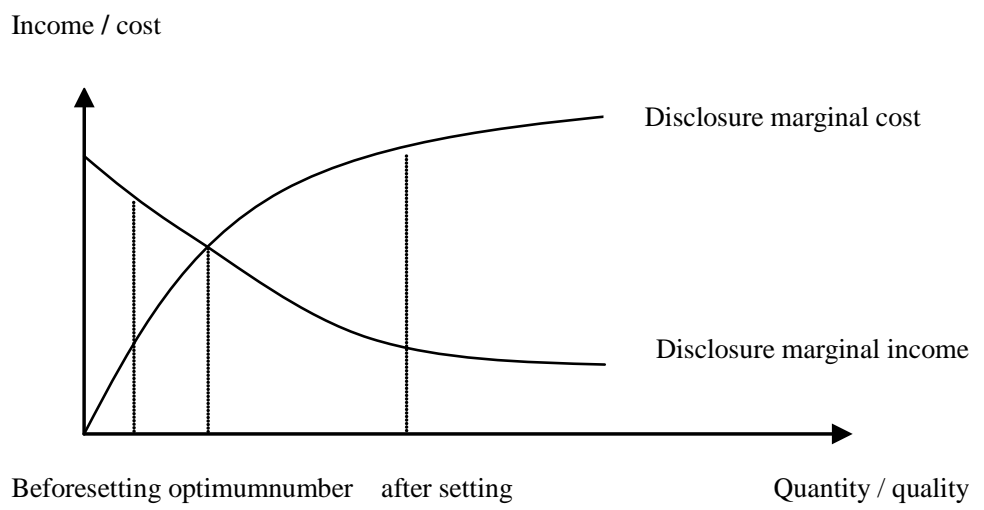

Figure 1. Enterprise information disclosure's cost and income figure.

ing standards [4]:

Formula (1): Representation operator's utility function $U(y, Q)$ is set to be continuous, strictly increasing, quasi concave and twice differentiable, there into: $y$ is a pure private goods, $Q$ is a pure public goods.

$$
Q=\sum_{i=1}^{n} q i
$$

Formula (2): The public good voluntary provision’s Nash Equilibrium Level determined by the Formula (1) is

$$
Q=\sum_{i=1}^{n} q i^{*}, q^{*}=q 1^{*}, \cdots, q i, \cdots, q N^{*}
$$

Formula (3): The condition of public goods provision's Pareto optimality is

$$
\sum[(U i / Q) /(U i / v i)]=p
$$

In other words,

$$
(U j / Q) /(U j / y i)=p-(U i / Q) /(U i / y i)
$$

It can be seen that the level of Pareto optimality's public goods provision is higher than the Nash equilibrium's provision level. The reason is that the consumption of public goods can be "free riding". As long as any operator thinks that someone else will provide more public goods, it will make response to providing little. Since it would lead to insufficient supply of public goods, the government is asked to provide or help. On one hand, the extra satisfaction which a good accounting standard brings some people in society is larger than the cost for which others pay to support this approach or behavior and make sacrifice. On the other hand, giving up a number of other similar criteria is the price of implementation of a criterion.

\section{Conclusion}

To sum up, from a global perspective, the government monopolies the formulation right of common accounting standards unlimited to "produce" of accounting standards. However, any formulation and implementation of accounting standards cost and this kind of production must be constrained by people's effective demands. Only those accounting standards which truly reflect the objective economic law and meet with accounting's developing directions and international conventions are "realistic" and "reasonable" and have vivid vitalities. Therefore, according to public choice theory and policy analysis theory, we can see that the high-quality accounting standards can be formulated in the case of the government's leading and other relevant stakeholders' common participations. Accounting standards are a result of both a "consensus" reached by all relevant stakeholders after repeated dice games and a relevant stakeholders' collective selection under public choice theory.

\section{References}

[1] Yang, X.Y. (2001) The Theory of Cultural Differences between China and the United States and the Establishment of 
Accounting Standards in China. Journal of Shandong University of Finance, 56, 75.

[2] Chen, H.H. (2003) The Stakeholder Theory and Empirical Research of Enterprises. The Dissertation Library, 95-96.

[3] Wang, Y.C. (2004) Accounting Standards Guide and Profit Manipulation of Listed Company. The Dissertation Library, 8.

[4] Lin, Z.G. and Xu, H. (2007) Accounting Standards Research: Character Setting and Enforcement. Economic Management Press, Beijing. 
Scientific Research Publishing (SCIRP) is one of the largest Open Access journal publishers. It is currently publishing more than 200 open access, online, peer-reviewed journals covering a wide range of academic disciplines. SCIRP serves the worldwide academic communities and contributes to the progress and application of science with its publication.

Other selected journals from SCIRP are listed as below. Submit your manuscript to us via either submit@scirp.org or Online Submission Portal.
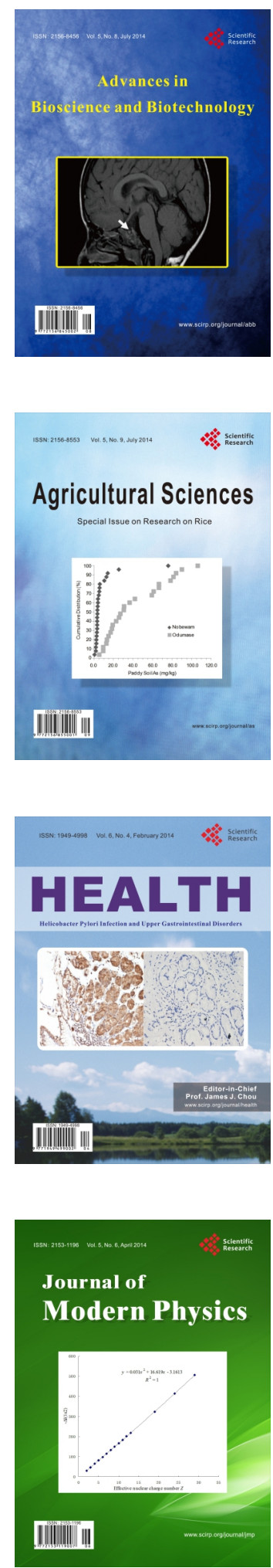
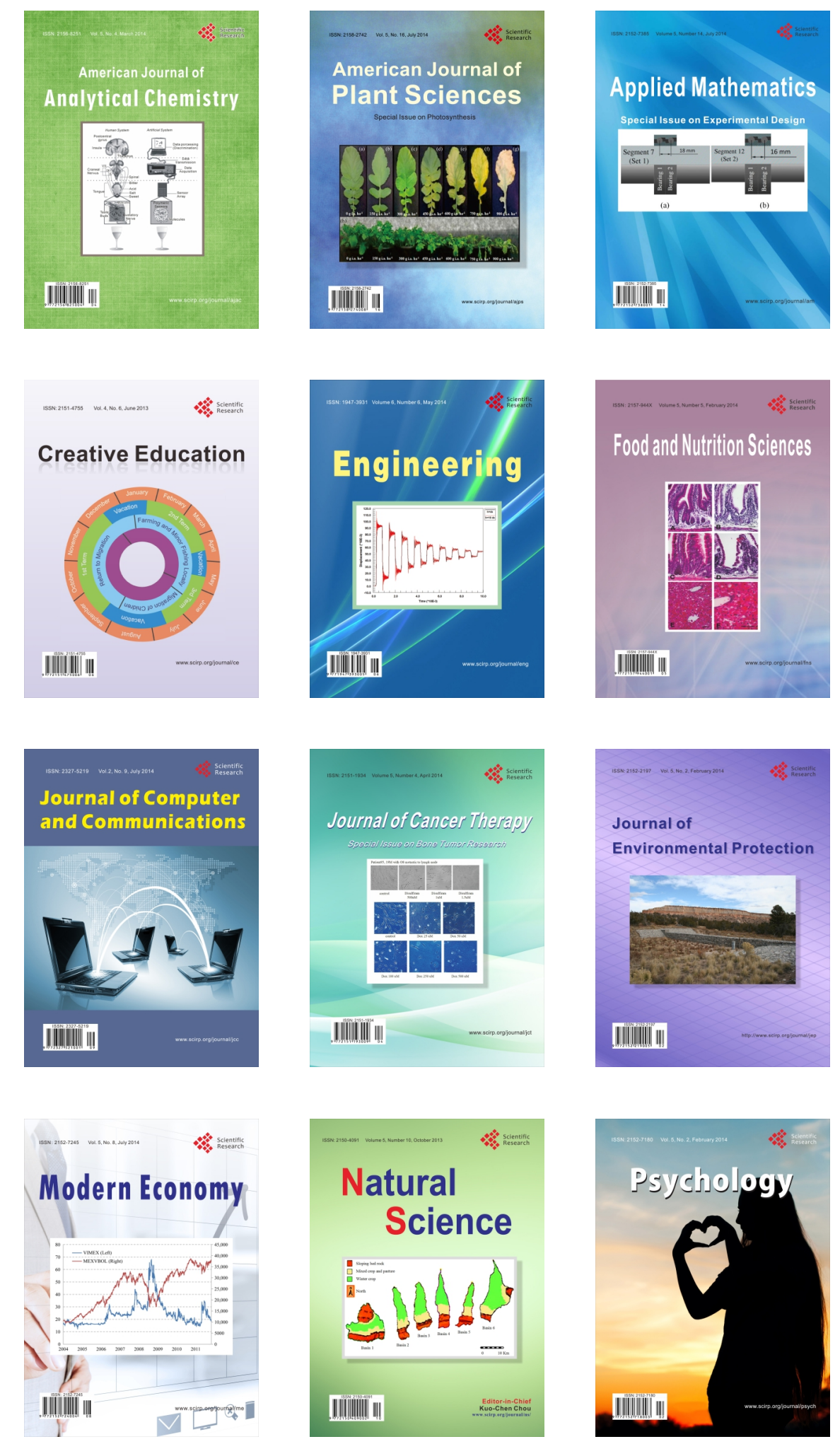